Article

\title{
Sustainability of Impact Sourcing Initiatives in Higher Education for Graduates' Employability
}

\begin{abstract}
Aini Aman (1D)
Faculty of Economics and Management, Universiti Kebangsaan Malaysia, UKM Bangi 43600, Selangor, Malaysia; aini@ukm.edu.my

Abstract: Impact sourcing (ImS) initiatives in higher education play important roles in the employability of graduates, especially in the global business services (GBS) industry. This study explores the sustainability of ImS in higher education institutions (HEIs) for graduates' employability. This study used qualitative research methodology, collecting data from related documents, observations, interviews, and focus groups with selected students, lecturers, and industry practitioners. The data were analyzed using Sen's capability framework, with the primary objective of analyzing individual capabilities-specifically, conversions, resources, and capabilities. The findings show that ImS could improve future graduates' technical and soft skills, thereby enhancing their employability in the GBS industry. Some constraints that need to be overcome include the infrastructure, rewards, and incentives, as well as system reliability. This study contributes to the development of the capability framework for ImS initiatives in relation to the employability of graduates and other marginalized communities. The conversions, resources, and capabilities should be considered when assessing the impact of ImS. In addition, this study contributes to the talent pool agenda with a specific focus on ImS and graduates' employability.
\end{abstract}

check for

updates

Citation: Aman, A. Sustainability of Impact Sourcing Initiatives in Higher Education for Graduates' Employability. Sustainability 2021, 13, 8. https:/ / dx.doi.org/10.3390/su13010008

Received: 27 November 2020 Accepted: 16 December 2020 Published: 22 December 2020

Publisher's Note: MDPI stays neutral with regard to jurisdictional claims in published maps and institutional affiliations.

Copyright: @ 2020 by the author. Licensee MDPI, Basel, Switzerland. This article is an open access article distributed under the terms and conditions of the Creative Commons Attribution (CC BY) license (https: / creativecommons.org/ licenses/by/4.0/).
Keywords: impact sourcing; graduates' employability; industry-academia collaboration; global business services; higher education

\section{Introduction}

Global business services (GBS) refers to the integration of services that include information and communication technology (ICT), finance and accounting (F\&A), human resources (HR), and engineering design and services under one organizational roof to capture additional value through savings from lower cost resources and access to higher skilled labor in different locations throughout the world [1]. GBS industry is highly affected by the Fourth Industrial Revolution (4IR), with rapid digital transformation in most of their systems and processes. GBS firms require graduates to possess the right skills and experiences in addition to their respectable degree. GBS firms require graduates with adequate digital and data literacy, innovativeness, and an entrepreneurial spirit; they must be flexible when dealing with complexities as they will be co-working not only with humans, but also robots. Higher education institutions (HEIs) in Malaysia produce thousands of graduates every year, but most graduates are unemployable in GBS firms due to their lack of necessary technical and soft skills [1].

In this study, graduates' employability refers to the set of skills and knowledge that make an individual more likely to secure his/her chosen occupations(s) in line with his/her competencies (e.g., knowledge and skills). The Malaysia Graduate Employability Blueprint 2012-2017 released by the Ministry of Higher Education, reports that graduates lack several key characteristics, such as a strong command of English, the right attitude, and the ability to solve problems, engage in teamwork, share expertise, respond to new technologies, be innovative and creative, and utilize numerical evaluation. Malaysia Higher Education 4.0 aims to produce highly creative graduates with the ability to think critically in order 
to meet the demand in 4IR. New thinking is required to deliver sustainable services and simultaneously generate employment opportunities. Such soft skills can be learned and developed in a situated learning environment [2]. Other researchers [3] suggest that companies should work closely with HEIs to guide students in acquiring and developing the essential skills in order to enhance their employability.

Impact sourcing (ImS), which is an emerging sub-field of GBS [4,5], was recently introduced in Malaysia to overcome the mismatch of talent and increase the employability of graduates in the GBS industry. ImS is an outsourcing of business or information technology (IT) services to third parties that employ disadvantaged individuals who do not have many opportunities for stable employment to provide outsourcing services [6] These include those who live in rural areas, those without access to secondary or tertiary education, and educated individuals in areas of high unemployment. ImS emphasizes the socio-economic impacts it brings to these individuals and the community in which it operates. To the international development community, $\operatorname{ImS}$ could be a response for a more active role of business enterprises in poverty alleviation programs $[7,8]$. At the national or community level, it is claimed that $\operatorname{ImS}$ has produced benefits, including increased employment opportunities for disadvantaged individuals, such as youth.

Some recent literature $[6,9-11]$ has provided a basic understanding of social development through information technology outsourcing (ITO) and business process outsourcing (BPO) initiatives in commercial relationships and the need for strong industry-academia collaboration [12]. However, studies have not yet assessed the impact of ImS on graduates' employability [7,10]. Some assessments on ImS on social development are available [13], but they are insufficient to explain the sustainability of ImS in HEIs for graduates' employability. This paper responds to this research gap and further explores the sustainability of ImS in HEIs for graduates' employability using Amartya Sen's capability framework [14-16].

This study aims to explain the sustainability of ImS in higher education for graduates' employability, particularly in the GBS industry, using Sen's capability framework. The capability framework offers a set of conceptual tools that focus on the achievement of individual capabilities, with the primary objective of analyzing conversions, resources, and capabilities. The research questions are: (1) What are the conversions, resources, and capabilities that could enable the potential and achieved capabilities for graduates employability and ensure sustainable ImS initiatives in HEIs? (2) How do ImS initiatives in HEIs overcome the constraints that inhibit the potential and achieved capabilities for graduates' employability? Using Sen's capability framework, this study will contribute to the development of the capability framework for ImS projects in relation to the employability of graduates and other marginalized communities. The remaining sections present the literature review and conceptual framework, methodology, findings, and analysis as well as the discussion and conclusion.

\section{Literature Review}

The literature on sourcing is growing. It started with outsourcing, offshore outsourcing, nearshoring, legal services outsourcing, business process outsourcing, crowdsourcing, open sourcing, ImS, and many more areas. Although the employment effects from local innovation activities and knowledge spillovers from other regions require high-skilled employees and have less demand for low-skilled employees [17], low-skilled employees are still needed in ImS. There is an emerging phenomenon of $\operatorname{ImS}$ that aims to transform people's lives, families, and communities through meaningful employment in digitally enabled services [10].

Researchers have begun to examine ImS and its related concepts [18,19]—namely, ethical sourcing, sustainable global outsourcing [9], micro-work [20], corporate social responsibility (CSR) in outsourcing [21], social outsourcing [22], and rural sourcing [23]. Much of the empirical work on ImS has focused on case studies of ImS service providers or the organizations that sell ITO and BPO services; only a few studies have focused on the impact of ImS on employees' development. 
Previous research [6] on social ITO as a promoter of development in India has provided understanding on how social ITO activity is interpreted from the perspective of employees who provide data services for the market and from the perspective of the social enterprise that balances its market orientation with its social development goals. The findings show that social ITO can provide a variety of developmental advantages to rural poor communities, leading to policy implications for governments and development agencies.

Another researcher [23] studied a special type of prison employment program: the hiring and training of prisoners to perform business services using a computer. They found evidence that the main benefits of prison sourcing for business services include good financial compensation, work habit development, productive occupation of time, development of business skills, and the elevation of self-efficacy and status. Unfortunately, they did not have data about the impact on future prospects.

Additional research [13] assessed the social development impacts of a commercial outsourcing organization practicing ImS as its CSR to provide employment opportunities to marginalized rural women through ICT. Using Amartya Sen's capability approach [16] from the development literature as a guiding framework, this study analyzed social development impacts of ImS that enabled the capabilities of marginalized outsourcing employees. It highlighted the restrictive and enabling conversion and resource factors that may influence the overall capabilities of marginalized outsource employees.

A more recent study [24] explored how ImS ventures frame their activities to marginalized communities. It identified the difficulties faced by ImS ventures in operationalizing their strategic intent. More specifically, the paper provided insights into how different and diverse framings are used by ImS ventures to influence the local community. The paper suggested that framings related to progress, family, material benefits, and egalitarianism can help overcome the inevitable tensions and misunderstandings with the community. The study provided specific insights that communities resist ImS ventures for two main reasons: (1) the perceived incompatibility of the ImS model with local norms and belief systems and (2) perceptions of inequality stemming from the merit-based recruitment strategies underpinning the model. It suggested that it would be interesting to study how ImS ventures' strategies vary across different social, cultural, and geographical settings.

Most ImS is best run as a (social) enterprise where commercial and social goals are simultaneously emphasized or pursued. Alternatively, ImS could be run in a privatepublic partnership or academia-industry model to cater for disadvantaged communities, particularly unemployable graduates $[25,26]$. Deeper understanding is needed on the issues and challenges unique to this model to ensure the sustainability of ImS initiatives in higher education by assessing the impact of ImS initiatives in enhancing graduates' employability.

The availability of a good ICT infrastructure allows for the vibrant presence of shared service outsourcing (SSO) firms and strong government support, which are key enablers of ImS in Malaysia [27]. The challenges for ImS success in Malaysia include low English proficiency and high attrition rates among $\operatorname{ImS}$ workers and the absence of micropayment providers. Nevertheless, such challenges could be overcome by realizing the potential of ImS with full government support. Although the findings contribute to the formulation of potential strategies and policies in ensuring the growth of $\operatorname{ImS}$ in Malaysia, there is a need to understand how sustainable ImS could contribute to graduates' employability.

This study uses Sen's capability framework $[13,14,28]$ by considering three key elements: conversions, resources, and capabilities. The capability framework offers a set of conceptual tools that focus on the achievement of individual capabilities. Previous literature [6,28-31] has proposed different approaches to operationalize the capability framework. The restrictive and enabling conversion factors that influence the overall capabilities of marginalized outsourced employees provide a limited discussion on the impact on the individual level, especially on the individual's potential capabilities and achieved capabilities [13]. This research will extend Sen's capability framework [13] by providing a further understanding of enhancing graduates' employability. Table 1 presents the suggested theoretical framework. 
Table 1. Theoretical framework.

\begin{tabular}{|c|c|c|}
\hline Key Elements & Sen's Capability Framework & ImS and Graduates Employability \\
\hline \multirow{5}{*}{ Conversion } & \multirow{5}{*}{$\begin{array}{c}\text { All elements that may enable or restrict an } \\
\text { individual from being employed, such as a lack of } \\
\text { skills, lack of resources, cultural constraints, and } \\
\text { family support }\end{array}$} & Individual-Motivation for learning \\
\hline & & Self-belief \\
\hline & & $\begin{array}{c}\text { Social-Awareness about ImS, Family support, and } \\
\text { encouragement }\end{array}$ \\
\hline & & Environmental-Distance and travel issues \\
\hline & & Technology—Awareness of ICT/Software tools \\
\hline Resources & $\begin{array}{l}\text { All tangible resources that act as capability input } \\
\text { and opportunities provided by the outsourcing } \\
\text { service provider to extend capabilities or minimize } \\
\text { the effect of restrictive conversion factors. }\end{array}$ & $\begin{array}{l}\text { Tangible Resources-Closely located office building, } \\
\text { office furniture, good internet connection } \\
\text { Intangible Resources-Peer encouragement, } \\
\text { professional help and support, learning and working } \\
\text { environment (e.g., flexible learning and working } \\
\text { hours, provision of training) }\end{array}$ \\
\hline Capabilities & $\begin{array}{l}\text { A set of potential and achieved capabilities that the } \\
\text { impact sourcing initiative may have enabled in } \\
\text { marginalized outsourcing employees }\end{array}$ & $\begin{array}{l}\text { Economic capabilities, educational } \\
\text { capabilities, individual capabilities, professional } \\
\text { capabilities, and ICT usability capabilities. }\end{array}$ \\
\hline
\end{tabular}

Source: Malik et al. (2016).

Conversion factors should include elements that may enable/restrict individual opportunities or choices (capabilities) of working as an outsourced employee [13]. These could be categorized as individual conversion factors, social conversion factors, environmental conversion factors, and technology conversion factors. The individual conversion factors may include self-belief and motivation for learning as well as competency in English language and ICT competency [12,13]. Social conversion factors may include awareness about ImS and ICT as well as family support. Environment conversion factors include distance to commute $[6,13]$. Technology conversion factors may include the ability or knowledge to use computers or ICT $[13,28]$.

Resource factors include all tangible resources that act as capability input and opportunities provided by the outsourcing service provider to extend capabilities or minimize the effect of restrictive conversion factors [13]. These resources are categorized into tangible and intangible resources. The tangible resources may include physical working resources and ICT equipment, while intangible resources may include peer support, comfortable learning, working environment, and the provision of training. The availability of good ICT infrastructure, vibrant presence of SSO firms, and strong government support are found to be key enablers of ImS [26]. The support from the top management is important to motivate users in technology usage. This could be done through continuous discussion, training, and coaching [32]

Capability factors are sets of potential and achieved functioning that outsourcing employees can achieve as a result of resources provided by the ImS organization [13]. Six types of capabilities were identified from the data set: economic capabilities, educational capabilities, individual capabilities, professional capabilities, and ICT usability capabilities [13]. The ImS Labs aim to emulate the work-integrated learning concept, where students get hands-on experience to work on a project. The most important benefit of a work-integrated learning program is building students' employability skills [32]. By using the lab, "artificial experience" is brought into the education program. The lab benefits the students by improving their performance and increasing graduates' employability [33]. The lab is also expected to improve students' technical core competencies and enhance their soft skills. The importance of having creative and social intelligence as a substantial share of employment in service occupations could be replaced by service robots [29].

\section{Methodology}

This study uses an interpretive qualitative research approach [34] to provide an understanding of ImS project assessment in enhancing graduates' employability as the 
interpretive approach assumes that social reality is shaped by human experiences and social contexts. In this study, the social context refers to a case study of ImS in Malaysia.

Malaysia is known as the third best location of outsourcing and GBS locations, as determined by AT Kearny, after India and China. The best locations are measured based on several factors, such as financial attractiveness, people skills and availability, business environment, and digital resonance. GBS industry is identified as a key sector that will add high-value jobs to the economy. However, the shortage of talent may create hurdles to achieving the aim. The feedback from the industry indicates that a "mismatch" in skills and talent exists and that many graduates are not appropriately equipped to face the working world, particularly in the new rapidly growing industry, such as that of the GBS. Most graduates are not hired due to a lack of specific skills and experiences required by GBS firms [1].

In order to overcome the issues of talent in the GBS industry, the Malaysian government initiated three pilot ImS programs targeting different marginalized communities: (1) the graduate community; (2) the blind community, and (3) the rural community. This study only focuses on the third program, which targets the graduate community as a marginalized group. The case study in this research included three $\operatorname{ImS}$ initiatives, subsequently known as ImS Labs (see Table 2), which has been running continuously since 2012 in a university, later known as Uni-R. Uni-R is one of the top research universities in Malaysia.

Table 2. Summary of Impact sourcing (ImS) Projects.

\begin{tabular}{cc}
\hline ImS Project & Project Info \\
\hline & Client: Accounting Firm and Small Medium Entrepreneurs \\
No. of Students: 550 \\
Services: Accounting Transactions \\
2012-2018 \\
Client: ITO Firm \\
No. of Students: 150 \\
NSS Lab 2 & Data Analytic Services: Image and Video Processing \\
& 2014-2016 \\
& Client: BPO Firm \\
No. of Students: 40 \\
Services: Data Profiling \\
2017-2018
\end{tabular}

Source: Author.

ImS Lab 1 started in 2010 with a pilot project involving final-year students helping small businesses by managing their finances. The project continued to expand its services from providing financial and accounting services to other business process outsourcing. The clients also expanded from micro to small and medium enterprises (SMEs) as well as accounting firms. One of the accounting firms, later known as Chen, set up its extended office at Uni-R to ensure the sustainable delivery of accounting outsourcing jobs from the $\mathrm{lab}$ to its clients. Most of the work has used cloud-based accounting and business software. To date, the ImS Lab 1 has trained more than 1200 graduates and services to more than 600 clients.

ImS Lab 2 was set up to provide hands-on training to graduates, expose them to real working experiences in the information technology outsourcing (ITO) industry, and thereby improve their opportunities for later employment in the GBS industry. An ITO firm, later known as SIG, agreed to bring some of its existing work to the university. Meanwhile, University A agreed to provide facilities to set up the ImS Labs and promote the outsourcing work to targeted groups of students. In this client-provider relationship, the ITO firm was the client and University A was the service provider. ImS Lab 1 involved almost 150 students who were trained with on-the-job training. The lab operated from 2014 to 2016, with most of the outsourcing jobs being big data analytics services and image and video processing. 
ImS Lab 3 involved a project with a business process outsourcing (BPO) company, later known as SELL. Similar to ImS Lab 2, the ImS Lab 3 aimed to provide on-the-job training to students in order to gain working experience. The arrangement was similar to ImS Lab 2, where the BPO firms promoted their outsourcing work to targeted students. The type of outsourcing jobs received from the BPO firm is related to data profiling and internet marketing. Because of some issues, the project only lasted for a year and involved only 40 graduates from different faculties in Uni-R.

Primary data collection involved in-depth interviews and focus groups, both of which used open-ended interview questions designed based on Sen's capability framework in order to get more in-depth information on the issues being studied. The questions covered the issues and challenges faced by the participants as well as benefits gained by the participants. The open-ended questions included three aspects of the capability approach: conversion factors, resources, and capabilities. Nevertheless, participants were free to deviate from the topic if they wanted to. This study used purposive sampling [35] and selected students, academicians, and industry partners who participated in the ImS project initiatives in the selected university in order to provide an in-depth understanding of sustainable ImS initiatives in the university.

This study involved a total of $16 \mathrm{~h}$ and $30 \mathrm{~min}$ of interviews and focus groups (Table 3). The interviews involved asking individuals while the focus groups involved discussions based on open-ended interview questions. Interviews were conducted face-to-face and lasted between 30 and $60 \mathrm{~min}$. The interviews were conducted at the respondents' office. The focus groups were conducted in the Uni-R with a group of $\operatorname{ImS}$ workers who were students and graduates participating in each ImS Lab with the purpose of getting a further understanding of the issues faced by the $\operatorname{ImS}$ workers. In addition to interviews and focus groups, the data collection also included documentary evidence from both primary and secondary sources, such as minutes of meetings, emails, and internal memos. Triangulation of the data allowed a comprehensive understanding of issues and is often viewed as a form of data validity.

Table 3. Interview details.

\begin{tabular}{cccc}
\hline Firm & Respondents & Interviewee Position & Minutes \\
\hline & Focus Group 1 & Focus Group 1: 4 ImS workers & 110 \\
& Focus Group 2 & Focus Group 2: 5 Academicians & 80 \\
ImS Lab 1 (Data & Respondent 1 & Managing Director (Industry) & 60 \\
Analytic Services) & Respondent 2 & Senior Manager (Industry) & 40 \\
& Respondent 3 & ImS Worker 1-Leader & 30 \\
& Respondent 4 & ImS Worker 2 & 35 \\
& Focus Group 3 & Focus Group 3: 4 ImS workers & 120 \\
& Respondent 5 & ImS Worker 3 - Leader & 60 \\
ImS Lab 2 & Respondent 6 & ImS Worker 4-Leader & 60 \\
(Account Services) & Respondent 7 & ImS Worker 5 & 60 \\
& Respondent 8 & ImS Worker 6 & 120 \\
ImS Lab 3 (Data & Focus Group & Focus Group 4: 5 ImS workers & 100 \\
Profiling) & Focus Group 6 & Focus Group 5: 4 Industry partners & 80 \\
& & Total Hours & $16 \mathrm{~h} \mathrm{30} \mathrm{min}$ \\
\hline
\end{tabular}

Source: Author.

The data analysis started with the transcription of interviews and focus groups and followed with the identification of issues through coding and theming. Interpretations were carried out through multiple readings of the transcripts and triangulated with relevant documents and reports collected during data collection. These were followed by intensive periods of discussions among research team members. Findings and discussions are framed within the suggested theoretical framework and relevant literature. Finally, a report is produced accordingly. 


\section{Findings and Discussion}

The findings of this study are discussed according to the three aspects of the capability approach: conversion factors, resources, and capabilities.

\subsection{Conversion Factors}

Conversion factors that may enable or restrict students' opportunities to work at the ImS Lab. Previous research [13] found that individual, social, environmental, and technology conversion factors are significant.

The findings show that the primary individual conversion factors that enable students participation in ImS initiatives are the motivation to learn and earn. Although earning money is the main goal, they are more motivated by the opportunity to learn. One of the respondents explained: "Honestly it is one of our main goals ... to earn money. In addition, I have never been involved in the data processing system ... so I want to learn that too" (Respondent 3). Other students indicated their motivation to join $\operatorname{ImS}$ work mainly because of the opportunities to gain experience and knowledge and use the latest technology in the ImS work. According to one respondent, "I joined to get an experience in the accounting field, such as making data entry, learning more about accounting software, and using it practically" (Respondent 5). This is similar to the findings of previous studies [12,13] that highlighted individual conversion factors, including self-belief and motivation for learning.

In this study, most students at Uni-R come from low-income families. They are used to working while studying to cover their expenses at the university. Some of them work parttime at fast food restaurants. The norms of working part-time while studying are a social conversion factor that enable students to continuously participate in the ImS initiatives. In addition, their interest in helping micro and small business owners to manage their businesses and accounts is another important social conversion factor. As emphasized by one of the students: "The purpose I joined is to get experience preparing a real client's accounts using software... At the same time, I can help small businesses because we charge affordable rates compared to the high prices charged by professional accounting firms. It makes me want to help them" (Respondent 6).

In addition to individual and social aspects, environment conversion influences the students' decision to participate in the ImS project. Most students prefer flexible locations rather than fixed locations. A flexible location may be possible only for the type of work that uses cloud-based platforms. However, not all jobs can be done online. Some jobs require consistent monitoring and hands-on training. This contributed to less commitment from the students. "At first, I thought we can do the work anywhere anytime, but later I was told that the work has to be done in the training lab. I cannot really commit" (Focus Group 4). Another respondent explained that "the location to do work should be flexible, because my hostel is quite far from the lab and I have to walk a distance just to come here (Lab). So, if we were given flexible time and location to do the work, I can find free time to do the job" (Respondent 5). This is consistent with previous studies that found that distance for a commute may inhibit the motivation to work in $\operatorname{ImS}[6,13]$.

\subsection{Resource Factors}

The findings indicated the need for intangible resources (e.g., a continuous job supply, flexibility of working hours, payment structure) and tangible factors (e.g., reliability of the system and Internet) in order to extend capabilities or minimize the effect of restrictive conversion factors.

It is important that service providers provide a continuous job supply in order to sustain students' excitement to participate in the ImS project. As indicated by one of the students who participates in the ImS project, "once you get the permission to promote the job to friends, the project suddenly stops ... because they said there was a problem with their client. At that time, students were already excited to work because of salary rate at RM6 per hour. Only a month later they started with the video analytic job" (Respondent 3). However, this is not possible as sometimes there is less demand from clients, making it 
difficult to get a new job. As highlighted by one of the companies participating in the ImS project, "the key issue here is demand from clients ... their awareness of ImS is low" (Respondent 2). Another respondent explained that "we expect a big bulk of jobs to come from the government, but it is not happening ..." (Respondent 8). The continuous job supply from clients or BPO firms plays an important role in the sustainability of the ImS project [25].

According to the students who participate in the ImS project, they need to be told about the payment structure before they start any work. It could be based on the number of hours or amount of work done. For example, in the job related to receipt processing, they prefer payment based on the number of receipts: "Probably we need flexible time to do work. Like what we did before ... data entry. Actually, they will pay us according to the number of receipt that we processed. For example, on the day we are not busy, we can do more, but on the day that we do not have much time, we just spend less hours" (Respondent 4). These merit-based recruitment strategies can help overcome the inevitable tensions and misunderstandings among the ImS participants [24].

In addition, the findings indicate the request from students that pay should be based on the number of hours, especially for jobs related to profiling, which requires hours of data cleaning, searching, and verification. As emphasized by Respondent 7, "before we start the job, we need to know the pay rate because we really want to know how much we will get for our effort... Whether it is based by hour or by number of company profiles that we completed. The pay structure must be fair and encouraging. At the moment, the pay is based on the number of profiles completed but sometimes we spend long hours to complete the profiles, but we cannot get the information. We wasted our time as we didn't get paid for the effort" (Focus Group 4). This finding supports previous research [23] showing that good financial compensation was significant to ensure the sustainability of ImS projects.

Tangible resources such as internet infrastructure and systems are important resources, especially for jobs requiring a certain technology platform to complete efficiently. As one student remarked, "there was a day when we came to do work, there is no internet. It was a waste of time for us waiting for almost one day, but the internet was not available" (Respondent 3). Often the blame on failure to provide a reliable system and internet connection was put on the university. As raised by Respondent 1, "they (the university) have to be on par with their international counterparts, they have to scale up. We have engaged consultants to evaluate the platforms (service providers) and make suggestions to the providers to improve their systems." Furthermore, the operating system was highly dependent on the technology platform used by the BPO company. In most cases, the system is not reliable and contains errors. As indicated by one of the students, "the video was not clear and repetitive with serial numbers. They want us to detect customer behavior, but it is repetitive and confusing" (Respondent 4 ). Both the university and industry professionals should work closely together to ensure the stability of the system and infrastructure. The findings indicate that the importance of a good ICT infrastructure and industry-academia collaboration are the key enablers of ImS in Malaysia [26].

\subsection{Capability Factors}

The findings of this study have identified individual, educational, and professional capabilities as the set of potential and achieved capabilities for the sustainability of $\operatorname{ImS}$ initiatives at the university.

Individual capabilities included the skills and knowledge acquired when performing the ImS work. Some students claimed that they acquired leadership skills while managing the clients' assignments. Some students were appointed as leaders and were responsible for managing clients' work and distributing tasks among the team. As one of the leaders explained, "as a leader, we need to distribute tasks; for example, if we meet the client, there is one member who will be talking more than others and one member will take notes. Besides, when we do data entry, two other members will be given the role of data entry. 
Therefore, we distributed the task among the team: Some of us will meet the client and others will do the data entry" (Respondent 5).

They also acquired skills in managing the team and conflicts. Most students have a chance to be the team leader. They must manage a team especially when conflict occurs. This is further explained by one of the team leaders: "Working in a group allows tasks to be completed more quickly through the distribution of tasks between group members; however, conflicts sometimes occur when there are too many ideas and complications to select because each member insists on their ideas. Therefore, in our group, the leader should play the role on getting agreement among team members." (Respondent 6). The development of soft skills in managing teams and conflicts is crucial for their future careers. The challenges of managing teams and conflicts while performing ImS work, in some ways, contributes to the sustainability of ImS initiatives. This was expressed in the studies of prison sourcing for business services [23].

The most important findings are that the ImS initiatives contribute to graduates' employability. The ImS work developed their professional capabilities. One of the graduates involved in the ImS initiatives explained this as follows: "A lot of knowledge and skills that I acquired during the previous ImS projects were useful for my current job as an audit assistant. We learned how to use software and how to perform internal audits. We learn how to deal and communicate with clients in a professional way. In classroom lectures, I only learned the audit framework, but in ImS Lab, I performed audit tasks in real business environments" (Respondent 4). Another graduate added that the job in ImS Lab helped him with professional accounting papers: "In ImS Lab, we learned about GST [Goods and Services Tax] and practically performed GST reporting. The knowledge and skills helped us when we took the Association of Chartered Certified Accountants (ACCA) accounting professional papers on taxes, as we were already familiar with GST" (Respondent 5). Their ImS Lab experiences also increased their chances for internships in GBS firms. As highlighted by one of the students who participated in data analytics outsourcing work, "I got my internship with Sime Darby Global Shared Services. My work is almost similar to the work I did with Sig (in ImS Lab 2). My experience working with the Sig project helped me to perform better during my internship" (Respondent 4). These comments support the findings of previous studies $[13,33]$ on achieving capabilities.

The work experiences at ImS Labs benefitted future graduates by improving their technical and soft skills, thereby increasing their professional capabilities and enhancing their employability. These outcomes could contribute to the sustainability of ImS initiatives in HEIs to enhance graduates' employability.

\section{Conclusions}

In short, this study identified the conversion, resource, and capability factors that contributed to the sustainability of ImS initiatives in HEIs for graduates' employability. One of the important conversion factors was the motivation of students to learn and earn. Students were motivated to learn new skills in a real business environment while earning reasonable pay for their efforts. The key resources required for sustainable ImS initiatives in HEIs include the continuous supply of jobs, flexibility of time and space, good internet facilities, and attractive pay. These were also the main challenges in ImS initiatives. Industry partners and top management at the university should collaborate and share resources to overcome such challenges. The industry should provide a continuous job supply and the necessary internet and technology required for $\operatorname{ImS}$ work [25,32]. The industry should also allow students to perform jobs on their own free time and in their own space. This can be possible only if the work uses appropriate cloud computing technology. The potential and achieved capabilities [35] found in this study were soft skills (e.g., leadership skills and ability to manage teams and conflicts). In addition, students developed professional skills that they found to be useful in their future careers, thereby enhancing their employability [36]. 
Theoretically, this study provides empirical evidence of factors required for sustainable ImS initiatives in HEIs to enhance graduates' employability. Following a recent study [13] using Sen's capability framework, this study identified the conversion, resource, and capability factors that contribute to the sustainability of ImS initiatives in HEIs. Although some researchers $[9,13]$ examining impact sourcing have focused on marginalized communities of the poor in rural areas, this study looked at graduates in HEIs who are marginalized because of employment opportunities. Recent HEI graduates were not hired because they did not have work experience. This study contributes to the GBS and sourcing literature, specifically in terms of the aspects of producing and retaining talent [25]. It also contributes to the understanding of the socio-economic impacts of ImS initiatives in HEIs. When students gain work experience in real business environments and improve the necessary skills required by future employers, they also earn some pocket money, thereby improving their socio-economic status. Previous research [26] has indicated that low English proficiency and the absence of micropayment providers are ImS challenges in Malaysia. This study also found that time, space, pay, and internet facilities are the main challenges.

Practically, this study suggests that a sustainable ImS project in HEIs requires strong industry-academia collaboration as well as student commitment. Top management in HEIs should be responsible for administering the program, set up the enrollment processes, monitor students' experience, and manage crises. At the same time, industry practitioners should be willing to work closely with students and academicians. The industry should be careful when outsourcing work to HEIs. Appropriate outsourcing activities could enrich students' learning experiences as they are expected to plan their schedules, commit their time, use judgment in making decisions, and perform the tasks successfully. Students must take necessary actions to ensure that the program contributes toward their career objectives, makes logistical arrangements to participate in the program, and evaluates their experiences.

The limitations of this study could be considered for future work. First, the scope of this study is limited to ImS projects at HEIs in Malaysia. Future studies might explore the sustainability of ImS projects in other HEIs, such as colleges or schools in different locations for more varieties and further understanding of issues and impacts of ImS. Second, this study focused only on capability framework in analyzing the sustainability of ImS projects at HEIs, which may only allow for the generalization to similar contexts. The sustainability and capability issues may be different in other contexts or settings. Future research could also investigate other types of capabilities in other contexts that could contribute to the sustainability of $\operatorname{ImS}$ initiatives.

Funding: This research was funded by a research grant from Universiti Kebangsaan Malaysia (grant number UKM GUP-2016-48 and EP-2019-003).

Conflicts of Interest: The author declares no conflict of interest.

\section{References}

1. Aman, A.; Yunus, Y.M.; Maelah, R.; Embong, Z.; Mohamed, Z.M.; Adznan, S.; Ahmad, A.A.; Nurzafira, Z.; Fernandez, D. Talent Pool for Global Business Services: Industry-Academia Collaboration. Asian J. Account. Gov. 2017, 8, 85-91. [CrossRef]

2. Tymon, A.; Harrison, C.; Batistic, S. Sustainable Graduate Employability: An Evaluation of 'Brand Me' Presentations as a Method for Developing Self-confidence. Stud. High. Educ. 2020, 45, 1821-1833. [CrossRef]

3. Succi, C.; Canovi, M. Soft Skills to Enhance Graduate Employability: Comparing Students and Employers' Perceptions. Stud. High. Educ. 2020, 45, 1834-1847. [CrossRef]

4. Falck, O.; Heblich, S. Corporate Social Responsibility: Doing Well by Doing Good. Bus. Horiz. 2007, 50, 247-254. [CrossRef]

5. Porter, M.E.; Kramer, M.R. Creating Shared Value. Harv. Bus. Rev. 2011, 89, 62-77.

6. Madon, S.; Sharanappa, S. Social IT Outsourcing and Development: Theorizing the Linkage. Inf. Syst. J. 2013, 1, 1-17.

7. Prahalad, C.K.; Hart, S.L. The Fortune at the Bottom of the Pyramid. Strategy Bus. 2002, 26, 54. [CrossRef]

8. Smith, A.; Pezeshkan, A. Which Businesses Actually Help the Global Poor? S. Asian J. Glob. Bus. Res. 2013, 2, 43-58. [CrossRef]

9. Babin, R. Assessing the role of CSR in outsourcing decisions. J. Inf. Syst. Appl. Res. 2008, 1, 3-14.

10. Carmel, E.; Lacity, M.C.; Doty, A. The Impact of Impact Sourcing: Framing a Research Agenda. In Information Systems Outsourcing; Hirschheim, R., Heinzl, A., Dibbern, J., Eds.; Springer: Berlin/Heidelberg, Germany, 2014. 
11. Lacity, M.; Carmel, E.; Rottman, J. Rural Outsourcing: Delivering ITO and BPO Services from Remote Domestic Locations. Computer 2011, 44, 55-62. [CrossRef]

12. Cecchini, S.; Scott, C. Can Information and Communications Technology Applications Contribute to Poverty Reduction? Lessons from Rural India. Inf. Technol. Dev. 2003, 10, 73-84. [CrossRef]

13. Malik, F.; Nicholson, B.; Morgan, S. Assessing the Social Development Potential of Impact Sourcing. In Socially Responsible Outsourcing Technology, Work and Globalization; Nicholson, B., Babin, R., Lacity, M.C., Eds.; Palgrave Macmillan: London, UK, 2016.

14. Sen, A. Commodities and Capabilities; North Holland: Amsterdam, The Netherlands, 1985.

15. Sen, A. The Standard of Living; Cambridge University Press: Cambridge, UK, 1987.

16. Sen, A. Development as Freedom; Oxford University Press: Oxford, UK, 1999.

17. Frey, C.B.; Osborne, M.A. The Future of Employment: How Susceptible are Jobs to Computerization? Technol. Forecast. Soc. Change 2017, 14, 254-280. [CrossRef]

18. Heeks, R. Theorizing ICT4D Research. Inf. Technol. Int. Dev. 2006, 3, 1-4. [CrossRef]

19. Heeks, R. Information Technology Impact Sourcing. Commun. ACM 2013, 56, 22-25. [CrossRef]

20. Gino, F.; Staats, B.R. The Microwork Solution. Harv. Bus. Rev. 2012, 90, 92-96.

21. Babin, R.; Nicholson, B. Corporate Social and Environmental Responsibility and Global IT Outsourcing. MIS Q. Exec. 2009, 8, 203-212.

22. Heeks, R.; Arun, S. Social Outsourcing as a Development Tool: The Impact of Outsourcing IT Services to Women's Social Enterprises in Kerala. J. Int. Dev. 2010, 22, 441-454. [CrossRef]

23. Lacity, M.C.; Rottman, J.; Carmel, E. Impact Sourcing: Employing Prison Inmates to Perform Digitally Enabled Business Services. Commun. Assoc. Inf. Syst. 2014, 34, 913-932. [CrossRef]

24. Sandeep, M.S.; Ravishankar, M.N. Impact Sourcing Ventures and Local Communities: A Frame Alignment Perspective. Inf. Syst. J. 2016, 26, 127-155. [CrossRef]

25. Aman, A.; Ahmad, A.A.; Yunus, Y.M.; Embong, Z.; Maelah, R. Overcoming Talent Shortage through Impact Sourcing. J. Pengur. 2018, 54, 51-59. [CrossRef]

26. Ismail, S.A.; Heeks, R.; Nicholson, B.; Aman, A. Analyzing Conflict and Its Management within ICT4D Partnerships: An Institutional Logics Perspective. Inf. Technol. Dev. 2018, 24, 165-187. [CrossRef]

27. Ismail, S.A.; Aman, A. Impact Sourcing Initiatives in Malaysia: An Insight through Porter's Diamond Framework. In State-ofthe-Art Theories and Empirical Evidence; Said, R., Mohd-Sidek, N., Azhar, Z., Anuar Kamarudin, K.A., Eds.; Springer: Singapore, 2018.

28. Robeyns, I. The Capability Approach: A Theoretical Survey. J. Hum. Dev. 2005, 6, 93-114. [CrossRef]

29. Aldieri, L.; Makkonen, T.; Vinci, C.P. Spoils of Innovation? Employment Effects of R \& D and Knowledge Spillovers in Finland. Econ. Innov. New Technol. 2019, 1-24. [CrossRef]

30. Frediani, A.A. Sen's Capability Approach as a Framework to the Practice of Development. Dev. Pract. 2010, $20,173-187$. [CrossRef]

31. Nussbaum, M. Women and Human Development: The Capabilities Approach; Cambridge University Press: Cambridge, UK, 2000.

32. Yunus, Y.M.; Aman, A.; Keliwon, K.B. The Role of Business Leaders in Information Technology Innovation in the New Era of Disruptive Technology. Asian J. Account. Gov. 2019, 12, 133-142.

33. Fraser, S.; Deane, E. Getting Bench Scientists to the Workbench. In Proceedings of the UniServe Science Scholarly Inquiry Symposium, Sydney, Australia, 5 April 2002; Fernandez, A., Ed.; University of Sydney: Sydney, Australia, 2002 ; pp. $38-43$.

34. Walsham, G. Doing Interpretive Research. Eur. J. Inf. Syst. 2006, 15, 320-330. [CrossRef]

35. Fallows, S.; Steven, C. Building Employability Skills into the Higher Education Curriculum: A University-wide Initiative. Educ. Train. 2000, 42, 75-83. [CrossRef]

36. Alkire, S. Choosing Dimensions: The Capability Approach and Multi-dimensional Poverty. 2007. Available online: https: / / papers.ssrn.com/sol3/papers.cfm?abstract_id=1646411 (accessed on 22 December 2020). 